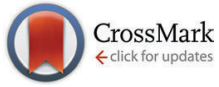

Cite this: Phys. Chem. Chem. Phys., 2017, 19, 4893

DOI: $10.1039 / c 7 c p 90021 j$

\section{Correction: New particle formation and growth from methanesulfonic acid, trimethylamine and water}

\author{
Haihan Chen, Michael J. Ezell, Kristine D. Arquero, Mychel E. Varner, \\ Matthew L. Dawson, R. Benny Gerber and Barbara J. Finlayson-Pitts* \\ Correction for 'New particle formation and growth from methanesulfonic acid, trimethylamine and \\ water' by Haihan Chen et al., Phys. Chem. Chem. Phys., 2015, 17, 13699-13709.
}

rsc.li/pccp

In the above paper, particle formation from the reaction of methanesulfonic acid (MSA) with trimethylamine (TMA) was reported. In these studies, a cylinder containing a custom mixture of TMA in air from a commercial gas supplier was used. Recent work in this laboratory ${ }^{1}$ shows significantly less particle formation from the MSA-TMA reaction when the gas phase TMA is generated using a permeation tube where $\mathrm{NH}_{3}$ was not detected, and where the detection limits for $\mathrm{NH}_{3}$ were at least an order of magnitude smaller than those in the earlier work. We believe that the higher rates of particle formation reported earlier are due to the presence of some unknown contaminants (likely $\mathrm{NH}_{3}$ at concentrations lower than the detection limit of a less sensitive instrument used for analysis at that time) in the commercial custom mixture. We have confirmed in separate experiments that particles formed by reaction of MSA with TMA from permeation tubes increased significantly upon addition of $\mathrm{NH}_{3}$. This does not change the conclusions of the paper that the MSA-TMA reaction forms particles, that water increases particle formation in this system and that this reaction is likely to occur in air. It does, however, provide a cautionary note on the quality and reliability of gas mixtures of amines from commercial gas suppliers.

The Royal Society of Chemistry apologises for these errors and any consequent inconvenience to authors and readers.

\title{
References
}

1 H. Chen and B. J. Finlayson-Pitts, Environ. Sci. Technol., 2017, 51, 243-252. 